\title{
NIPE is related to parasympathetic activity. Is it also related to comfort?
}

\author{
Julien De Jonckheere ${ }^{1,2} \cdot$ Laurent Storme ${ }^{1,3}$
}

Received: 4 February 2019 / Accepted: 5 February 2019 / Published online: 13 February 2019

(c) Springer Nature B.V. 2019

Neurodevelopment of newborns can be impaired by many "stressful" events, with long-term consequences: pain, discomfort, hypoxia, even maternal stress has a negative impact. Experimental and clinical studies have shown that stress and/ or pain during the perinatal period could negatively influence the long-term programming of the hypothalamic-pituitary-adrenal (HPA) axis, which could account for abnormal responses to stress later in life, and may increase the risk of developing metabolic and cardiovascular diseases in adulthood $[1,2]$. Perinatal stressful events are probably related to impaired autonomic nervous system (ANS) activity and a decreased parasympathetic activity in particular, which can easily be measured by modern monitors using e.g. heart rate variability analysis (HRV) [3, 4]. The University Hospital of Lille, France, has been part of several clinical studies evaluating how an HRV based index, the Analgesia Nociception Index (ANI, MDMS, Loos, France) could help evaluate the analgesia/nociception balance during general anesthesia [5] but also how ANI evidenced a decreased parasympathetic activity during a procedural pain in children [6].

A similar HRV evaluation of the ANS has been adapted to the specific case of newborns: the Newborn Infant Parasympathetic Evaluation (NIPE, MDMS, France) reflects continuously and non-invasively the parasympathetic tone, which has been shown to decrease significantly in newborn infants after a painful surgical procedure [7] or after instrumental assisted delivery [8]. Even if the clinical benefit of increasing the parasympathetic activity cannot be fully grasped yet, we showed that NIPE was significantly higher after facilitated tucking [9] or skin to skin contact in neonates [10]. Continuous assessment of comfort is quite challenging in the

Julien De Jonckheere

julien.dejonckheere@chru-lille.fr

1 EA 4489-Perinatal Environment and Health, University of Lille, 59000 Lille, France

2 INSERM CIC-IT 1403, CHU Lille, 59000 Lille, France

3 Department of Neonatology, CHU Lille, 59000 Lille, France newborn infant, especially in neonatal intensive care units. Adapted scales, such as the EDIN [11], are routinely used in NICU to assess pain/discomfort at the bedside. However, EDIN is usually measured every 4 to $8 \mathrm{~h}$ in clinical practice, whereas NIPE can be used continuously as a monitoring tool to alert healthcare providers in case of stress or pain. When used in NICU, the nurses have to be aware that NIPE is highly sensitive to environmental factors such as noise, light, feeding and sleep status, which should be controlled for a reliable interpretation of any NIPE change.

In this issue, Valencia-Ramos et al. used the NIPE measurements in parallel with the COMFORT behavioral scale (CBS) during nebulization in order to quantify pain and/ or discomfort related to the use of two different nebulizers in children with bronchiolitis. They observed significant variations in CBS and NIPE during nebulization. Moreover, CBS variations were significantly different between the two nebulizers whereas NIPE showed similar reactions of the ANS to nebulization, and didn't show any superiority of one nebulizer versus the other. These results also underline the fact that HRV analysis is independent from heart rate variations which are not specific of any given factor in the context of a Pediatric Intensive Care Unit (PICU). Variations of HRV measurements should be taken as information per se, as clinical assessment and behavioral scales-even if clinically validated - cannot easily be related to a given status of the ANS, that is either a parasympathetic prevalence (comfort) or a sympathetic activation (pain/stress). Only well conducted, prospective randomized clinical trials will show the benefit of "optimizing" the state of the ANS. The presented observational study illustrates only too well the difficulties clinicians are confronted to when "measuring" the well-being of their patients. As stated in the discussion chapter, NIPE and CBS were not evaluated in the same way: CBS was evaluated before (T1), during (T2) and after (T3) nebulization whereas NIPE variations were only measured in terms of absolute magnitude during the whole 
procedure. Such a difference in the way data were collected could explain in itself the lack of correlation between both.

\section{Compliance with ethical standards}

Conflict of interest JDJ is shareholders of and scientific consultant for Mdoloris Medical Systems (that commercializes NIPE monitor). LS reports no conflict of interest.

\section{References}

1. Barker DJ. Developmental origins of adult health and disease. J Epidemiol Community Health. 2004;58:114-5.

2. Spencer SJ. Perinatal programming of neuroendocrine mechanisms connecting feeding behavior and stress. Front Neurosci. 2013;7:109.

3. Heart rate variability. Standards of measurement, physiological interpretation, and clinical use. Task Force of the European Society of Cardiology and the North American Society of Pacing and Electrophysiology. Eur Heart J. 1996;17:354-81.

4. Oberlander TF, Grunau RE, Pitfield S, et al. The developmental character of cardiac autonomic responses to an acute noxious event in 4- and 8-month-old healthy infants. Pediatr Res. 1999;45:519-25.

5. Jeanne M, Delecroix M, De Jonckheere J, Keribedj A, Logier $\mathrm{R}$, Tavernier B. Variations of the analgesia nociception index during propofol anesthesia for total knee replacement. Clin J Pain. 2014;30(12):1084-8.

6. Avez-Couturier J, De Jonckheere J, Jeanne M, Vallée L, Cuisset JM, Logier R. Assessment of procedural pain in children using analgesia nociception index: a pilot study. Clin J Pain. 2016;32(12):1100-1104.

7. Faye PM, De Jonckheere J, Logier R, Kuissi E, Jeanne M, Rakza $\mathrm{T}$, et al. Newborn infant pain assessment using heart rate variability analysis. Clin J Pain. 2010;26:777-82.

8. Rakza T, Butruille L, Thirel ML, Houfflin-Debarge V, Logier R, Storme L, De Jonckheere J. Short-term impact of assisted deliveries: evaluation based on behavioral pain scoring and heart rate variability. Clin J Pain. 2018;34(5):445-449.

9. Alexandre C, De Jonckheere J, Rakza T, Mur S, Carette D, Logier $\mathrm{R}$, et al. Impact du cocooning et de la voix humaine sur le système nerveux autonome (SNA) de l'enfant grand prématuré. Arch Pediatr. 2013;20:963-8.

10. Butruille L, Blouin A, De Jonckheere J, Mur S, Margez T, Rakza $\mathrm{T}$, Storme L. Impact of skin-to-skin contact on the autonomic nervous system in the preterm infant and his mother. Infant Behav Dev. 2017;1:49:83-6.

11. Debillon T, Zupan V, Rayault N, Magny J, Dehan M, Abu-Saad H. Development and initial validation of the EDIN scale, a new tool for assessing prolonged pain in preterm infants. Arch Dis Child Fetal Neonatal Ed. 2001;85:36-41.

Publisher's Note Springer Nature remains neutral with regard to jurisdictional claims in published maps and institutional affiliations. 